\title{
O INSTITUTO MUSEU JAGUARIBANO EM ARACATI-CE: HISTÓRIA, MEMÓRIA E EDUCAÇÃO MUSEOLÓGICA
}

\author{
Antônio Roberto Xavier ${ }^{1}$ \\ José Ribamar de Lima ${ }^{2}$ \\ Lisimére Cordeiro do Vale Xavier ${ }^{3}$
}

\section{THE JAGUARIBAN MUSEUM INSTITUTE IN ARACATI-CE: HISTORY, MEMORY AND MUSEOLOGICAL EDUCATION}

\begin{abstract}
RESUMO
O objetivo deste artigo é demonstrar como o Museu Jaguaribano, após se tornar patrimônio histórico de Aracati, possibilita o acesso à história e à cultura locais através da educação e da memória. Nessa ótica, vislumbra-se primordial entender determinadas realizações humanas em diferentes contextos através do patrimônio material e/ou imaterial e o momento de inserção social a que pertenceu. O legado dessas realizações humanas está nos lugares de memória, como: cemitérios, templos, arquivos, bibliotecas, museus, dentre outros. É nesses lugares que visitantes fortuitos ou pesquisadores em geral podem encontrar explicações ou reflexões sobre a estada e o fazer humanos em diferentes e diversificados contextos.
\end{abstract}

Palavras-chave: História. Memória. Patrimônio. Museu Jaguaribano. Aracati-CE.

\begin{abstract}
The main objective of this article is to understand how the Jaguaribano Museum, after becoming historical patrimony of Aracati, allows access to the local history and culture through education and memory. In this perspective, it is envisaged that it is essential to understand certain human achievements in different contexts through material and / or immaterial patrimony and their moment of social insertion to which they belonged. The legacy of these human achievements is, above all, in places of memory, such as: cemeteries, temples, archives, libraries, museums, among many others. It is in these places that random visitors or researchers in general can find explanations or reflections on the stay and the making of humans in different and diverse contexts.
\end{abstract}

KEY-WORDS: History. Memory. Equity. Museum Jaguariban. Aracati-CE.

\footnotetext{
${ }^{1}$ Professor Adjunto da Universidade da Integração Internacional da Lusofonia afro-brasileira.

${ }^{2}$ Graduado em História pela Universidade Estadual do Vale do Acaraú - UVA; Bacharel em Direito e Especialista em Museologia ambas as formações pela Faculdade do Vale do Jaguaribe - FVJ.

${ }^{3}$ Doutoranda em Educação (UFC); Mestre em Planejamento em Políticas Públicas (UECE); Licenciada em Pedagogia e Letras (UECE).
} 


\section{Introdução}

Pesquisar, analisar e tentar compreender a história e a memória de determinada cidade ou coletividade, grupo social e/ou comunidade é um trabalho que requer no mínimo: observação, curiosidade, aproximação e investigação nos lugares de memória presentes no arcabouço patrimonial. Nesse sentido, escolhemos como fio condutor ou questão geradora de problema: como o Museu Jaguaribano, enquanto espaço educativo, desenvolve a disseminação da historiografia local, após se constituir como patrimônio histórico?

Para atender à problemática em alusão, ratificamos o objetivo central deste artigo, na perspectiva de demonstrar como o Museu Jaguaribano, após se tornar patrimônio histórico de Aracati, possibilita o acesso à história e à cultura locais por intermédio da educação e da memória.

Porém, essa perspectiva se torna mais estimulante e mais vívida na medida em que os dados colhidos em documentos, em livros antigos, na observação de objetos de uso pessoal ou impessoal, nos materiais encontrados em arquivos ou guardados em museus e nos relatos de pessoas que vivenciaram os acontecimentos nos mostram e nos levam a decifrar e a entender o que cada época ou pessoa do passado nos deixam a partir de seus registros. Um espaço que pode ser usado para contar esses fatos históricos são os museus. Considerando a realidade no município de Aracati, encontramos como exemplar o Instituto do Museu Jaguaribano, que, com o seu acervo, está contido nesse espaço de memória e de cultura. Nesse contexto, as visitas ao museu apresentam-se como a principal ferramenta de acesso para que variados tipos de públicos possam verificar, a partir do que está exposto, os momentos vivenciados por nossos antepassados.

Ao verificar cada objeto, o visitante se depara com um ser provocador, pois os objetos e os artefatos ali expostos são documentos que contam a história de um momento específico de uma sociedade. No passado, a esses objetos era atribuído um grande valor, devido apenas ao fato de pertencerem a grandes personagens da elite, por essa razão a eles era atribuída uma valorização fundamentada no proprietário, e não na importância do objeto como referente e representante de um contexto social, desconsiderando-se, assim, a participação dos demais grupos sociais, como africanos, indígenas, etc. 
Com um novo pensamento da História e uma nova abordagem museológica, hoje as peças não se apresentam apenas como objetos de celebração, mas, acima de tudo, de reflexão. Os objetos são estudados de forma a compreender a História do homem em seus vários aspectos sociais, econômicos, políticos e culturais, vivenciados de maneira a entender os momentos históricos de cada sociedade que passou. $\mathrm{O}$ visitante, observando através do que deixaram essas pessoas do passado, vai compreender e entender como viviam e de que maneira os membros dessa sociedade passada conviviam e se relacionavam, compreendendo a dinâmica do objeto no seu momento histórico, discutindo-o e comparando-o com o tempo atual.

Nesse contexto, particularmente, o Instituto do Museu Jaguaribano nos suscita interesse pelo fato de ser vanguardista na luta pela preservação do patrimônio histórico e cultural, como também por a ele serem atribuídas características de museu. Isso sem nos referirmos ao aspecto arquitetônico do Solar do Barão de Aracati, que teria pertencido a Antônio Pereira da Graça Filho, sede do Instituto do Museu Jaguaribano, que reflete a realidade dos diversos bens culturais do Aracati.

Metodologicamente este artigo foi construído a partir do método indutivo, com abordagem qualitativa. Quanto ao procedimento técnico, seguiu-se ao estudo de caso através de técnicas de observação direta sobre o objeto, auxiliado com análise empírica documental. Para tanto, foram realizadas observações de experiências e práticas do dia a dia com visitantes que possibilitaram uma leitura do contexto em que os objetos são percebidos e representados em seus significados e profundidade histórica, transformando-se em reais instrumentos ou peças extraordinárias, motivos de potente admiração por quem os observa e transcende na imensidão indelével da memória.

\section{Das origens e fundação do Instituto Museu Jaguaribano}

O Instituto Museu Jaguaribano tem por finalidade a preservação do patrimônio histórico e do acervo cultural representativo da região jaguaribana. Está localizado à Rua Coronel Alexanzito, $\mathrm{n}^{\circ}$ 743, antiga Rua Grande ou Rua do Comércio, no centro da cidade de Aracati. Nasceu oficialmente em 15 de novembro de 1968, quando o Dr. Hélio Ideburque Carneiro Leal, juntamente com um grupo de pessoas apaixonadas por história, decidiu que o patrimônio tanto de Aracati quanto da região jaguaribana precisava ser cuidado e preservado. A criação e a organização de um museu em Aracati era uma ideia antiga, há muito acalentada pelos aracatienses estudiosos da História do Ceará ou por 
interessados na preservação do patrimônio histórico e do acervo cultural da zona jaguaribana. Vale ressaltar ainda que o prédio que abriga o Instituto é um imóvel de estrutura colonial que ainda mantém sua magnitude da época áurea do Aracati. O próprio prédio que hoje abriga o Museu Jaguaribano é um museu a céu aberto, uma belíssima construção imponente sinalizando sua importância desde os tempos do início de sua existência.

Na visão de Farias (2010: 2):

A construção histórica, discurso e idealização do museu da região jaguaribana passaram: pela decisão de optar em usar como sede o Solar do Barão de Aracati ou a Igreja de Nossa Senhora do Rosário das Almas; ações de captação de objetos para seu acervo; e implementação e treinamento de técnicos pelo Projeto Rondon para suas atividades.

Sua concretização foi tentada várias vezes sem que se chegasse a um resultado satisfatório, por motivos mais diversos. Certo é que, em mais de uma oportunidade, peças de valor científico ou puramente histórico foram coligidas para exposições que alcançaram êxito, chegando a sensibilizar profundamente a população da cidade. Em Fortaleza, um grupo de intelectuais aracatienses, cujos nomes deixamos de declinar para evitar omissões desagradáveis, mesmo involuntárias, pretendeu manter a entidade, que, todavia, teve curta existência, visando ao estudo e ao debate da história da região jaguaribana, especialmente em Aracati.

Com efeito, o Instituto do Museu Jaguaribano é chamado, nos termos próprios da edificação, de Prédio Solar número 743. O Solar é

[...] uma edificação bastante antiga, do início do século XVIII, que compõe o grupo de exemplares de casas e de sobrados que guardam relevantes histórias da era colonial e que, ao mesmo tempo, são tomados como representação da arquitetura produzida durante os três grandes ciclos econômicos do século XVII vivenciados pela cidade de Aracati, a saber: da pecuária, do charque (quando o seu porto passou a ser então o maior do Ceará, período áureo da economia aracatiense) e do algodão. [...] O Solar 743 constitui um dos testemunhos mais visíveis do processo de formação econômica, social e cultural da região. (Xavier; Fialho; Matos, 2016: 121). 


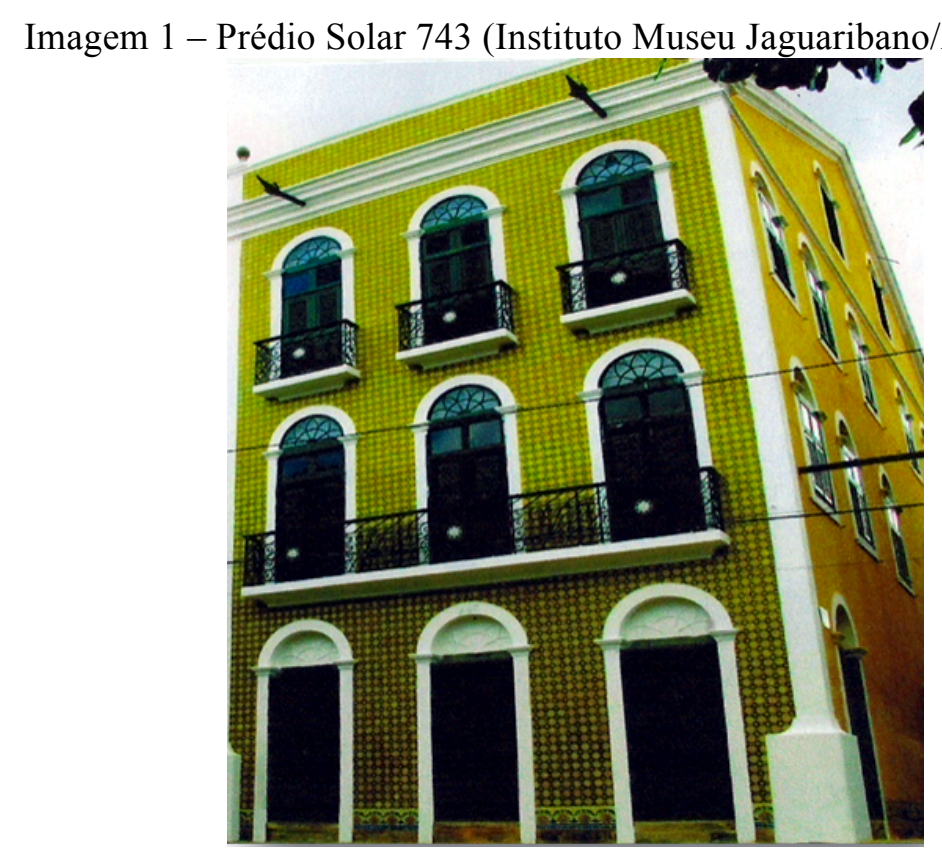

Fonte: Museu Jaguaribano.

O Instituto Museu Jaguaribano pode ser considerado a mais notável edificação da cidade, composta de quatro pavimentos, incluindo um sótão. A fachada é coberta de azulejos estampidos de origem portuguesa, tendo as janelas e parapeitos de ferro. Sua lateral é para o poente. A argamassa é constituída de cal e clara de ovo; logo, observamse o cuidado e a opulência da construção. O teto da laje do térreo é forrado e pintado; pode-se observar duas colunas de madeira. O piso do térreo é de cimento e tijolos; dos andares superiores os pisos são de madeira e todos os cômodos têm o teto forrado, exceto o sótão, que é de telha-vã.

Há uma escada caracol do segundo para o terceiro pavimento. No térreo, situamse a cozinha, o banheiro e as instalações sanitárias. Logo, observam-se o esmero e o capricho no acabamento dessa construção.

O prédio, que é ocupado hoje pelo Instituto Museu Jaguaribano, está tombado pelo Decreto Estadual no 16.237, datado de 30 de novembro de 1983, pelo Livro de Tombo Artístico, pertencente ao Serviço Social da Indústria (Sesi), a essa altura tendo como Diretor Regional o Major José Raimundo Gondim, industrial de larga visão e estudioso dos problemas vitais do Nordeste.

O referido Diretor, em louvável iniciativa, colocou à disposição dois pavimentos do antigo prédio recentemente adquirido por essa instituição. Durante muito tempo, o museu ocupou somente esses dois espaços muito limitados. As peças ficavam todas juntas, estando o restante da casa utilizado para as atividades do Sesi. Posteriormente todo o espaço do prédio foi dado em comodato, facilitando, assim, a distribuição dos 
objetos, com a seguinte condição: o antigo casarão deveria ser cuidado e preservado para que o museu se instalasse totalmente em todos os cômodos da antiga residência colonial (Xavier; Fialho; Matos, 2016).

Após essa decisão, o primeiro passo seria de recuperação, já que o prédio apresentava sinais de desgaste ocorridos ao longo de sua existência. O Sesi, não podendo assumir tal responsabilidade, fez a doação definitiva para o Museu Jaguaribano. A solenidade de doação do sobrado pelo Sesi se deu em 18 de março de 2000; aconteceu no prédio onde funcionou o Círculo Operário, hoje Teatro Francisca Clotilde.

A partir desse momento, cabia ao Instituto Museu Jaguaribano a recuperação, que veio através do Instituto do Patrimônio Histórico Artístico Nacional (Iphan). A recuperação levou um período de cinco anos; hoje o museu está funcionando normalmente, o qual funciona anexo a um prédio vizinho que foi desapropriado pelo governo do Estado. Esse prédio anexo também está inscrito no Sistema Estadual e Nacional de Museus por atender aos requisitos exigidos. O museu conta com sócios efetivos e coletivos, os quais, com suas contribuições, tornam possível seu funcionamento. "Um museu não é uma instituição estática, onde se guardam objetos em lugares mais ou menos adequados. Um museu é mais do que isto. Antes de tudo, um museu é uma unidade de ensino e pesquisa. É vida, é escola, é ciência, é arte” (Leal, 1978: 18).

\section{Do conteúdo interno do Instituto Museu Jaguaribano}

O acervo do Museu Jaguaribano é bastante diversificado e está dividido em oito seções:

1. História, que compreende: a numismática, a heráldica, a filatelia, a sigilografia, a indumentária, o mobiliário, a ourivesaria, os objetos de uso pessoal e doméstico, tais como: vidros, cristais, opalinas, louças e porcelanas. Ainda na seção de História, encontra-se o material de construção, como telhas, tijolos, pinhas e balaústres; armaria; objetos de suplício usados no período da escravidão; placas comemorativas, bandeiras, bustos, esculturas, retratos, pinturas;

2. Arte Sacra, que compreende: os santos, os oratórios e os objetos de uso litúrgico; 
3. Artes, que compreende: a arquitetura;

4. Antropologia cultural e etnografia, que compreendem: o folclore, os costumes, o artesanato, os objetos indígenas, as flechas e os tacapes;

5. Arqueologia, que compreende: o material lítico pré-histórico ou primitivo: machados de pedra, lanças, flechas, cerâmicas;

6. Paleontologia, que compreende: os fósseis de fauna e flora;

7. Ciência, maquinaria e tecnologia, que compreendem: o tear, a máquina de coser, a máquina de escrever, etc.;

8. Arquivo histórico, que compreende: os documentos, as artes gráficas, a cartografia, os livros, os folhetos, os catálogos, os cartazes, os rótulos comerciais, a literatura de cordel, os livros de ata, os livros mercantis, os livros de escrituras públicas, os livros de registros civis e religiosos, as fotografias, as plantas de construção, as circulares, os editais, as revistas, os jornais, as cartas náuticas, o levantamento estatístico e a gravação de depoimentos de pessoas ilustres. Há também uma reserva técnica, na qual vários outros objetos estão guardados.

O conteúdo supracitado constitui a base característica de um museu, haja vista que um museu:

[...] é uma casa com espaços físicos definidos, aberta ao público e que guarda objetos adquiridos, construídos ou modificados de um certo contexto. Esses objetos ou materiais podem representar memórias infindáveis de uma certa época, tais como: sonhos, frustrações, alegrias, instituições, ilusões, sentimentos diversos, etc. No Museu estão os elos de ligação de tempos imortais que se entrelaçam e desenlaçam, tempos, lugares, culturas e pessoas diferentes e semelhantes, em certos momentos do existir. (Xavier, A.; Silva; Xavier, L., 2012: 243).

Mais recentemente, o Instituto Brasileiro de Museu (Ibram) passou a corroborar a decisão ocorrida na 20ª Assembleia Geral de Barcelona, de 6 de julho de 2001, na qual ficou postulado que museu pode e deve ser entendido como sendo:

[...] uma instituição permanente, sem fins lucrativos, a serviço da sociedade e de seu desenvolvimento, aberta ao público e que adquire, conserva, investiga, difunde e expõe os testemunhos materiais do homem e de seu entorno para educação e deleite da sociedade e que guarda, conserva, preserva e abriga representações do patrimônio cultural. (Xavier, A.; Silva; Xavier, L., 2011: 10). 
É com essa perspectiva educadora que o Instituto Museu Jaguaribano começou com a pretensão de cuidar e preservar objetos para que a posteridade tivesse acesso à sua história. Hoje traz uma proposta bastante interessante, não só para o público em geral, mas também para públicos específicos, como aqueles oriundos de escolas. Por meio de agendamento, os discentes dessas escolas podem visitar o museu e conhecer objetos que vão contar a história de sua sociedade, podendo, a partir do conhecimento das peças, fazer uma análise do momento social e histórico de sua cidade e de outros lugares.

\section{Das atividades museológicas no Instituto Museu Jaguaribano}

O Instituto Museu Jaguaribano mantém, desde a década de 1980, exposições temporárias que vão sempre de 15 de junho a 15 de julho de cada ano. São fotografias do Aracati antigo, jornais antigos de Aracati e de outras regiões do país, livros raros, papéis e documentos antigos. Promove também cursos em parceria com o Museu do Ceará e treinamentos para funcionários e pessoas que queiram aprender como funciona um museu, bem como palestras e eventos sociais; além disso, realiza lançamentos de livros. Também de 15 de novembro a 15 de dezembro, promove a exposição de artistas locais, que apresentam trabalhos em artes plásticas. Essa exposição, em algumas ocasiões, é acompanhada de oficinas que interagem com o público, tornando a exposição bastante interessante. Também existe um convênio com o município, por meio do qual as escolas municipais agendam suas visitas sem nenhum ônus.

A intenção de Eusébio não era só de fazer do museu um lugar de intelectuais, mas torná-lo, também, um lugar acessível ao público em geral, um espaço destinado ao conhecimento e à aprendizagem dos valores dignos de uma sociedade ideal, que valoriza e respeita as suas tradições. (HOLANDA, 2005: 33).

$\mathrm{Na}$ "geografia dos passos", o museu abre possibilidades para se tornar um objeto exposto na cidade, fonte de "educação patrimonial". Ora, é nesse sentido que o ensino de História não deve ser realizado somente na sala de aula, ou somente em museus. $\mathrm{O}$ objeto gerador, matéria-prima da reflexão histórica, não se localiza em lugares específicos. O que importa para o ensino de História não é "ir ao museu", mas usar a pedagogia do objeto no museu e em muitos outros territórios (RAMOS, 2004). O museu, como espaço de visitação, existe “[...] para estar inteiramente a serviço da 
comunidade" e, como tal, ele "[...] não pode abdicar de seu papel como instrumento crítico de recuperação, acesso e entendimento da extraordinária diversidade da experiência humana e do mundo em que vivemos" (RAMOS, 2004: 30).

Com efeito, o museu é território farto e abrangente de história, memória e cultura. Conforme Rezende (2009: 17-21):

\begin{abstract}
Quantas memórias estão presentes em cada objeto inventado? Quantos riscos humanos existem nas coisas que esclarecem sentimentos e escondem fugas, num vaivém da simultaneidade dos instantes [...]? Refletir sobre o museu, mas também sobre o que é trabalhar no museu. Anunciar saídas, apontar pressões, indicar o que fazer de cada um é importante e assegurar a manutenção do público, quando as relações não se configuram como espaços de poucos e representações das vaidades das minorias [...]. Há, portanto, uma dimensão pedagógica que tem de ser refeita, longe dos tecnicismos, mas próximas do afeto. Com isso, podemos atiçar a memória e não minimizar os depoimentos das experiências [...]. Cada fronteira que se abre na pesquisa histórica é uma afirmação de que as relações sociais se mantêm em todos os territórios. A fonte não é um objeto anônimo. Ela revela e esconde, entrelaça-se com subjetividades. Cria arquivos que não são papéis velhos ou falas desconexas [...].
\end{abstract}

Pensar assim é entender que o museu é um espaço de reflexão e de pesquisa sobre as vivências de sujeitos sociais em seus respectivos contextos, por mais antigo que sejam. Nos museus, encontramos as mais diversas representações sociais desses sujeitos.

\title{
Das visitas ao Instituto Museu Jaguaribano
}

Os visitantes do Museu Jaguaribano viajam por um mundo de conhecimentos até então por eles desconhecido, com coisas que chamam a sua atenção e, consequentemente, despertam a reflexão deles para a História, criando uma disposição nos indivíduos para que queiram saber mais e conhecer sobre a história dos objetos. Nesse contato com o objeto, os visitantes caminham para um perfeito entendimento da peça observada e tornam-se conhecedores do momento socioeconômico ou político em que o objeto esteve inserido, têm ciência sobre a participação dessa peça na História e sua importância na sociedade a qual pertenceu. Os objetos são dispostos por questões temáticas, com a identificação de cada um dentro de seu espaço compreensível, facilitando o entendimento pelos visitantes. 
O método do objeto gerador estimula nos observadores um jogo de perguntas com os objetos. Cada objeto inserido na cenografia - que por si só abre um leque para temas diferenciados - quando associado ao cenário e posto em diálogo com os demais objetos ou outras documentações, produz uma narrativa: “O ser dos objetos existe na relação com outros objetos e o ser humano. Falar dos objetos é falar da nossa própria historicidade" (RAMOS, 2004: 62).

Desenvolver políticas públicas de atendimento aos estudantes não significa transformar o museu em apêndice da escola nem descuidar da visita do público. Ao ter clareza sobre sua posição educativa, que passa pela pesquisa de acervo, montagem de exposições fundamentadas e atividades com as escolas, o museu torna-se mais didático, provocativo e lúdico, criando condições para um relacionamento mais profundo com os variados aspectos dos outros visitantes. Não se trata de promover ou reafirmar uma "escolarização" do museu, e sim de estudar a multiplicidade de papéis educativos que podem ser assumidos pelo espaço museológico (RAMOS, 2004).

As visitas que acontecem no Museu Jaguaribano são mediadas por um monitor, que explica aos visitantes cada peça que está exposta e seu significado dentro do processo histórico em que foram inseridas, facilitando a compreensão de cada objeto ali exposto. Fazer relações entre museu e educação, especialmente o ensino de História, implica reconhecer que, na sua própria definição, o museu sempre teve o caráter pedagógico -intenção nem sempre confessa -, bem como defender e transmitir certa articulação de ideias, seja o nacionalismo, o regionalismo, a classificação geral dos elementos da natureza, o elogio a determinadas personalidades, o conhecimento sobre certo período histórico e a chamada "consciência crítica". Vale ressaltar que é preciso ter plena consciência de que fazemos História a cada dia.

Qualquer museu é o lugar onde se expõem objetos, e isso compõe processos comunicativos que necessariamente se constituem na seleção das peças que devem ir para o acervo e no modo de ordenar as exposições. Tudo isso sempre se orienta por determinada postura teórica, que pode ir dos modelos de doutrinação aos parâmetros que estimulam o ato de reflexão (RAMOS, 2004).

Ao se entrar no espaço expositivo do Museu Jaguaribano, o objeto perde seu valor de uso: a condição utilitária. Quando perdem suas funções originais - as vidas que tinham no mundo fora do museu -, tais objetos passam a ter outros valores, regidos pelos mais variados interesses. O que merecia ficar no museu de feição mais tradicional era, em geral, o objeto da elite: a farda do general, o retrato do governante, a cadeira do 
político, a caneta do escritor, o anel de um bispo, tudo isso compunha o discurso figurativo da história de heróis e indivíduos de destaque.

Os objetos hoje têm seu valor não como peças a serem exaltadas pelo feito de seu dono, mas como instrumentos que fizeram parte da História, que podem nos dar uma referência do momento pelo qual passou. Atualmente os debates sobre o papel educativo do museu afirmam que o objetivo não é mais a celebração de personagens ou a classificação enciclopédica da natureza, e sim a reflexão crítica. Se antes os objetos eram contemplados, ou analisados, dentro da suposta "neutralidade científica", agora devem ser interpretados. Mudam, portanto, os "argumentos museais" e entra em voga a discussão sobre as tensões entre o "museu-templo" e o "museu-fórum", termos que ficaram no vocabulário museológico a partir das considerações de Duncan Cameron no início dos anos 1970 (RAMOS, 2004).

No cotidiano, usamos uma infinidade de objetos: desde a televisão até a roupa. Por outro lado, pouco pensamos sobre os objetos que nos cercam. Se pouco refletimos a respeito de nossos próprios objetos, a nossa percepção de objetos expostos no museu será também de reduzida abrangência. Sem o ato de pensar sobre o presente vivido, não há meios de construir conhecimento atinente ao passado. E o próprio conhecimento do presente já pressupõe referências ao pretérito.

Conhecer o passado de modo crítico significa, antes de tudo, viver o tempo presente como mudança, como algo que não era, mas que está sendo e que pode ser diferente, mostrando relações historicamente fundamentadas entre objetos atuais e de outros tempos através da memória. O museu ganha substância educativa, pois imbrica e implica relações entre o que passou, o que está passando e o que pode passar. Se aprendermos a ler palavras, é preciso exercitar o ato de ler objetos, de observar a história que há na materialidade das coisas, nos lugares de memória, como é o caso dos museus (NORA, 1984).

O espaço museológico se transforma em lugar de grande importância a partir do momento em que se coloca como instituição de pesquisa e de estudo. O museu que expõe estudos da cultura material tem condições para se transformar em espaço de insubstituível importância nos procedimentos de renovação pedagógica, trazendo para o ato de aprender o compromisso com o mundo vivido e os desejos de transformá-lo. Certamente a responsabilidade maior é do próprio museu: o compromisso de se colocar como instituição cultural e educativa. 
A experiência de observação e reflexão sobre o programa educativo de uma instituição cultural nos fez perceber que há subliminarmente um jogo de forças e tensões entre os diferentes campos disciplinares envolvidos nessas práticas comunicativas. Os campos da Museologia, do Patrimônio, da Educação e da Arte-Educação são campos de saberes distintos em disputa por poder e por espaço. Cada um deles tem seu próprio histórico de reflexões, debates e publicações sobre a função educativa dos museus, mas nem sempre essas experiências são compartilhadas. Um dos maiores desafios para a construção de um projeto interdisciplinar reside exatamente na criação de novas formas de conhecimento, a partir da transformação, baseada no diálogo, de práticas disciplinares com epistemologias diversas, uma necessidade crescente em nossa contemporaneidade. (CRETTON; PINTO, 2012: 144).

Mas isso não se faz de modo solitário. É preciso que haja um envolvimento de outras instituições, como as universidades, que formam os educadores, e as próprias escolas, que levam suas turmas para visitar o museu. Emerge, desse modo, uma questão de fundamental importância: os modos pelos quais as escolas e os professores fazem opções curriculares (RAMOS, 2004).

Nesse sentido é que professores de escolas e de universidades estão indo e buscando junto ao museu essa parceria, levando seus alunos para que tenham essa consciência de que os museus existem não só como espaços para expor objetos, mas também como lugares de educação.

\section{Conclusão}

A proposta central deste artigo foi a de demonstrar como o Museu Jaguaribano, após se tornar patrimônio histórico de Aracati, possibilita o acesso à história e à cultura locais através da educação e da memória.

Acreditamos que ficou consolidado no bojo do texto o pressuposto de que, para conhecermos com maior profundidade e representatividade a história de uma coletividade, comunidade, nação e/ou povo, é preciso conhecermos nossa cultura. Nesse contexto, insere-se a necessidade da pesquisa, de o público observar o como viviam nossos antepassados, os seus costumes, as suas crenças e os seus valores; através dessas informações, podemos saber como era a vida dessas pessoas. Para que isso seja possível, vamos buscar essas informações em uma fonte de grande importância, que são os museus, locais em que o visitante vai satisfazer sua curiosidade e, a partir da 
observação das peças, fazer uma análise dos objetos ali expostos de forma compreensível, entendendo o contexto histórico daqueles artefatos.

O Instituto Museu Jaguaribano, com seu acervo diversificado, como instrumento de pesquisa e de educação, traz essa proposta, possibilitando a públicos específicos, sejam oriundos de escola ou de universidades, ou a públicos diversos, a possibilidade de visualizar peças que vão nos contar como era a vida das pessoas em seus respectivos contextos históricos.

Buscar conhecer nossa história, seja ela local, regional ou nacional, é buscar inteirar-se socioculturalmente da formação e da estrutura mental de nossa realidade presente. Com base nesse conhecimento, podemos formalizar nossas opiniões a respeito das análises das peças, não mais como objetos celebrados ou admirados pertencentes a um personagem da elite ou de um homem importante da sociedade, mas como algo que fez parte da História, um objeto que causa no visitante um estranhamento, que se lhe apresenta como algo provocador. Diante desse estranhamento, a investigação começa e, a partir de então, a real compreensão do significado histórico dos objetos pode ser percebida por quem os olha.

A percepção acontece não como quem admira algo extraordinário, mas dentro de uma visão crítica de alguém que analisa e interpreta um ser provocador, daquilo que está à sua frente, com plena consciência do conhecimento do conteúdo histórico da peça observada. Olhar o objeto como um personagem que fala, que diz quem é, que conta quem foi, qual sua importância no seu momento histórico a que pertenceu, propiciando uma compreensão do objeto por quem o observa e analisa, facilitando, assim, entender seu momento sociocultural desde a perspectiva de um passado que serve a um presente que se postará no futuro.

\section{Referências}

BRASIL. Lei $\mathrm{n}^{\mathrm{o}}$ 11.906, de 20 de janeiro de 2009. Cria o Instituto Brasileiro de Museus (Ibram), cria quatrocentos e vinte e cinco cargos efetivos do Plano Especial de Cargos da Cultura, cria Cargos em Comissão do Grupo-Direção e Assessoramento Superiores (DAS) e Funções Gratificadas, no âmbito do Poder Executivo federal, e dá outras providências. Diário Oficial da União, Brasília, DF, 21 jan. 2009.

CEARÁ. Decreto Estadual n ${ }^{\circ} 16.237$, de 30 de novembro de 1983. Institui o Instituto Museu Jaguaribano em Aracati e dá outras providências. Diário Oficial do Estado, Fortaleza, $1^{\text {o }}$ dez. 1983. 
CRETTON, Anamaria Aziz; PINTO, Diana de Souza. Programas educativos em museus: um estudo de caso. Revista Museologia \& Interdisciplinaridade, Brasília, DF, v. 1, n. 2, p. 134-145, 2012.

FARIAS, Alex da Silva. Memória e cidade: a construção histórica do Instituto do Museu Jaguaribano (1965-1985). Projeto de pesquisa apresentado ao curso de mestrado Acadêmico em História da Universidade Estadual do Ceará em 2010, para o processo seletivo de inserção ao MAHIS.

HOLANDA, Cristina Rodrigues. Museu Histórico do Ceará: a memória dos objetos na construção da história (1932-1942). Fortaleza: Secult-CE, 2005.

LEAL, Hélio Ideburque Carneiro. Museu Jaguaribano. Aracati, 1978. (Mimeo).

Singelo documentário de alguns atentados ao patrimônio cultural da cidade de $\overline{\text { Aracati }}$ (1940-1994). Fortaleza: Universidade de Fortaleza, 1995.

NORA, Pierre. Entre mémoire et histoire: la problematique des lieux. In: GERON, Charles-Robert (Org.). Le lieux de mémoire. Paris: Gallimard, 1984. v. 2.

RAMOS, Francisco Regis Lopes. A danação do objeto: o museu no ensino de História. Chapecó: Argos, 2004.

REZENDE, Antonio Paulo. In: RUOSO, Carolina. O Museu do Ceará e a linguagem poética das coisas (1971-1990). Fortaleza: Museu do Ceará: Secult-CE, 2009.

SECRETARIA MUNICIPAL DE CULTURA. Departamento do Patrimônio Histórico. $O$ direito à memória: patrimônio e cidadania. São Paulo: DPH, 1992.

XAVIER, Antônio Roberto; FIALHO, Lia Machado Fialho; MATOS, Maria do Socorro de. Museu Jaguaribano: história, memória e descrição arquitetônica. Revista Eletrônica Documento/Monumento, Cuiabá, v. 20, n. 1, p. 119-128, 2016.

XAVIER, Antônio Roberto; SILVA, Ana Maria da; XAVIER, Lisimére Cordeiro do Vale. Museu: real espaço de educação, cultura, história e memória. In: VASCONCELOS, José Gerardo; SANTANA, José Rogério; FIALHO, Lia Machado Fiuza (Org.). História da educação: real e virtual em debate. Fortaleza: UFC, 2012. p. 242-260. 